\title{
Chapter 2 \\ How a Gene from Japan Revolutionized the World of Wheat: CIMMYT's Quest for Combining Genes to Mitigate Threats to Global Food Security
}

\author{
Thomas A. Lumpkin
}

In 1935, the work of Japanese scientist Gonjiro Inazuka to cross a semi-dwarf Japanese wheat landrace with two American varieties resulted in an improved semidwarf variety, known as Norin 10. Unlike other varieties, which stood taller than $150 \mathrm{~cm}$, the $R h t 1$ and $R h t 2$ genes present in Norin 10 reduced its height to $60-110 \mathrm{~cm}$. In the late 1940s Orville Vogel at Washington State University used Norin 10 to help produce high-yielding, semi-dwarf winter wheat varieties. Eventually, Vogel's varieties ended up in the hands of Norman Borlaug, who was working to develop rustresistant wheat in Mexico.

In 1953, Borlaug began crossing Vogel's semi-dwarf varieties with Mexican varieties. The result was a new type of spring wheat: short and stiff-strawed varieties that tillered profusely, produced more grain per head, and were less likely to lodge. After a series of crosses and re-crosses, the semi-dwarf Mexican wheat progeny began to be distributed nationally, and within 7 years, average wheat yields in Mexico had doubled. Borlaug named two of the most successful varieties Sonora 64 and Lerma Rojo 64, and it was these two varieties that led to the Green Revolution in India, Pakistan and other countries. This international exchange of ideas and germplasm - starting with genetic resources from Japan - ultimately saved hundreds of millions of people from starvation.

Fifty years on, farmers and societies face new challenges to feed rising populations, and wheat, along with its production and trade, epitomize the difficulties. The world's climate is changing; temperatures are rising in major wheat-growing areas and extreme weather events are becoming more common; natural resources are being depleted; new diseases are emerging; and yields are stagnating. Coupled with these difficulties, ever-increasing demand for wheat from a growing worldwide population

\footnotetext{
T.A. Lumpkin $(\bowtie)$

International Maize and Wheat Improvement Center (CIMMYT), Mexico, D. F., Mexico e-mail: t.lumpkin@cgiar.org
} 
and changing diets put pressure on grain markets, pushing up prices, disrupting free trade when drought or floods threaten crops in wheat-producing nations.

With offices and research stations in 14 countries including its headquarters in Mexico, the International Maize and Wheat Improvement Center (CIMMYT) is working to address these challenges through scientific research. CIMMYT's research is focused on sustainably increasing wheat and maize productivity, which includes actively contributing to a better understanding of the genetic basis of yield, as well as drought, heat and disease resistance. Through the Seeds of Discovery (SeeD) initiative, and other collaborations, CIMMYT is also broadening genetic variability and discovering new genes that will help increase yields and prevent crop losses to climate change or disease.

\section{The Origins of Norin 10}

Upon hearing of Orville Vogel's successes in incorporating the semi-dwarf genes from the Japanese Norin 10 variety into winter wheat, Norman Borlaug wrote to him in 1952 requesting that genetic materials containing the Norin 10 genes be used as parental lines in the Mexican wheat breeding program. A few months later a small number of seeds arrived in Mexico from three different $\mathrm{F}_{2}$ plants originating from the cross Norin $10 \times$ Baart and a small number of seeds from each of the five $\mathrm{F}_{2}$ plants from the cross Norin $10 \times$ Brevor (Reynolds and Borlaug 2006). With this simple exchange of communication and germplasm, so began one of the most extraordinary agricultural revolutions in history.

The journey of semi-dwarf wheat from Japan to Mexico may have begun in Korea in the third or fourth century, where short wheat varieties may have originated (Cho et al. 1993). From East Asia, wheat breeders in Italy, the USA and elsewhere began to seek and utilize dwarfing genes to breed for high yield, resistance to lodging and ability to produce more tillers than traditional varieties.

The lineage of the Norin 10 can be traced back to Daruma, a native Japanese short-straw variety (see Fig. 2.1) crossed with one soft "Fultz" and one hard wheat “Turkey Red" variety from the United States. 'Fultz' was first introduced to Japan

Fig. 2.1 Pedigree of Norin 10 (Reitz and Salmon 1968)

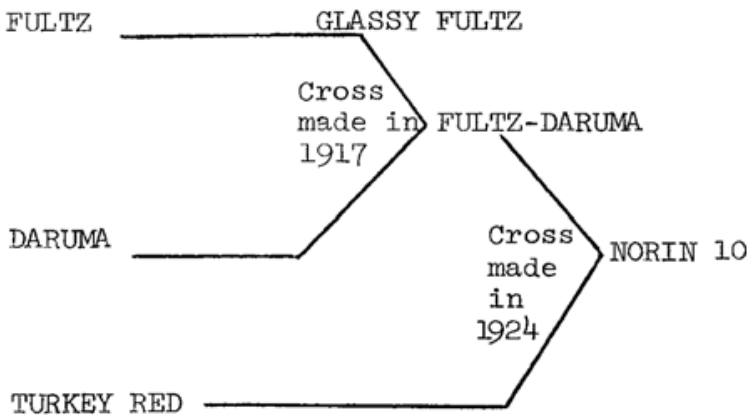


from the USA around 1892. The exact year that 'Turkey Red' arrived in Japan is unknown but it is thought to have been around the same time (Reitz and Salmon 1968). Fultz and Turkey Red were used in two significant crosses at the Central Agricultural Experiment Station in Nishigahara, Tokyo during the early twentieth century leading to the creation of Norin 10. First, in 1917 a variety called 'Glassy Fultz' was isolated from the 'Fultz' variety, and then crossed with Daruma to create 'Fultz-Daruma.' Then, in 1924 Fultz Daruma was crossed with Turkey Red (Inazuku1971). Pedigree lines were then transferred to the Konosu Branch Station, Saitama Prefecture where an $F_{2}$ plant was selected in 1926 and then sent to the Iwate-Ken Prefectural Station, in northeast Japan where the $\mathrm{F}_{3}$ was grown and final selections of this lineage were made. The final selection was released in 1935 and named Norin 10.

The term Norin is an acronym of the first letter of each word of the Japanese Agricultural Experiment Station as spelled out using Latin letters. The successes of Norin 10 are attributed to Mr. Gonjiro Inazuka, a Japanese wheat breeder who was chief of the Wheat Breeding Program at Iwate from 1930-1935 (Iwanaga 2009).

According to Reitz and Salmon (1968) records from the Iwate-Ken Prefectural Station show that Norin 10 was $55 \mathrm{~cm}$ tall $-13 \mathrm{~cm}$ shorter than the control variety Norin 1. Despite being seeded in rows $50 \mathrm{~cm}$ apart and on land that was heavily fertilized and irrigated, the plants only grew about $60 \mathrm{~cm}$ high and did not lodge (Reitz and Salmon 1968).

The semi-dwarf stature of the Norin 10 cultivar is controlled by the Rhtl and Rht2 genes (Pinthus and Levy 1983). Rht1 (Rht-B1b) and Rht2 (Rht-Dlb) have been used extensively over the last 60 years to develop high-yielding varieties that reduce plant height and resist lodging. The Rht genes produce shorter cultivars by 'decreasing the sensitivity of reproductive and somatic tissues to endogenous gibberellin' (Sial et al. 2002) which results in decreased internode length and reduced plant height.

\section{From Norin 10 to the Green Revolution}

Norin 10 began to attract international attention after a visit by Salmon SD, a renowned wheat breeder in the U.S. Department of Agriculture (USDA), to Morioka Agriculture Research Station in Honshu (Borojevic and Borojevic 2005). Salmon took some samples of the Norin 10 variety back to the United States, which were sent on to a joint Washington State University (WSU) /USDA project at Pullman, Washington (Reitz and Salmon 1968). At WSU in 1949, Dr. Vogel began to use these semi-dwarf varieties extensively and a series of crosses were made, including Norin $10 \times$ Baart and Norin $10 \times$ Brevor.

As previously mentioned, Vogel supplied the Norin $10 \times$ Baart and Norin $10 \times$ Brevor crosses to Dr. Borlaug and the Mexico wheat breeding program. In 1952 and 1953, the Mexican wheat program focused its efforts on tackling the problem of lodging (Borlaug 1981). With varieties such as Chapingo 52, Lerma Rojo 53 and Yaqui 50, the heavy application of nitrogen fertilizer led to severe lodging and yield loss. 
After unsuccessfully screening the entire USDA World Wheat Germplasm collection to find shorter and strong varieties, Borlaug wrote to Vogel and requested seed containing the Norin 10 dwarfing genes.

Borlaug detailed in 1981 that the first attempt at incorporating the Vogel genes into the Mexican varieties failed. He attributes this lack of success to the fact that the $\mathrm{F}_{3}$ plants produced from Dr. Vogel's seed were used as female parents and as a result were highly susceptible to rust.

The second attempt was successful and a new type of wheat with higher yield was evident in the $F_{1}$ and $F_{2}$ progeny from those crosses. So much so, that from 1957 nearly all of the Mexican wheat breeding efforts focused on the Norin $10 \times$ Brevor derivatives.

Not only was dwarfness of stature introduced into the crosses from the Norin 10 derivities, but also a number of other genes had been introduced, which increased the number of fertile florets per spikelet, the number of spikelets per head and the number of tillers per plant. (Norman Borlaug 1981)

At first, Borlaug encountered a number of problems with progeny from the cross Norin $10 \times$ Brevor $\times$ Mexican varieties:

1. High degree of male sterility leading to promiscuous outcrossing

2. Poor grain that was shriveled, soft and with low gluten content

3. Susceptibility to stem and leaf rust.

The new and innovative shuttle breeding program, introduced by Borlaug, between El Batán, located at an altitude of 2,249 $\mathrm{m}$ in the Central Mexican highlands, and Ciudad Obregón located in the irrigated desert in the Northern Sonora Valley, meant that two generations per year could be grown to speed up selection against the above mentioned problems. The exposure of the breeding materials to contrasting locations and diverse environmental constraints also allowed Borlaug and his team to select for a broader range of disease resistances (Ortiz-Garcia et al. 2006).

By 1962, 10 years after Vogel first supplied seed of the Norin 10 Japanese semidwarf progeny to Borlaug, two high-yielding semi-dwarf Norin 10 derivatives, Pitic 62 and Penjamo 62, were released for commercial production (Reynolds and Borlaug 2006). As Fig. 2.2 indicates, these wheat varieties then led to a flow of other high-yielding wheat varieties, including Siete Cerros 66, which at its peak was grown on over 7 million hectares in the developing world (Reynolds and Borlaug 2006).

\section{The Impact of the Green Revolution}

Although the Green Revolution's roots were in Mexico, South Asia's abundant wheat harvests were its hallmarks and key milestones in global agricultural development. 


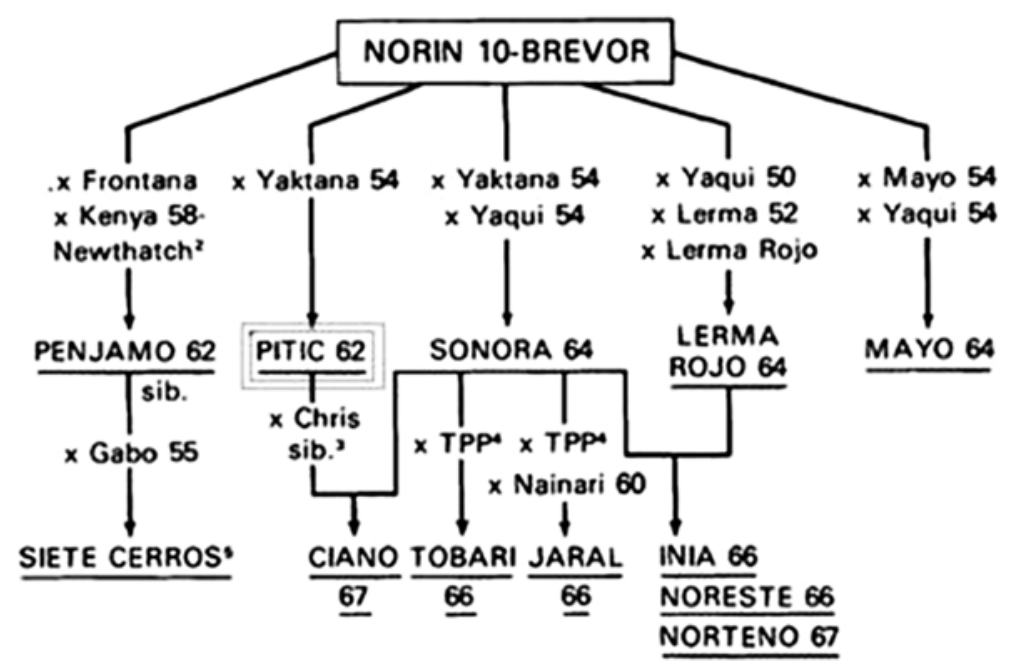

Fig. 2.2 Genealogy of early semi-dwarf CIMMYT wheat varieties (University of Minnesota 2012)

In the early 1960s South Asia was facing mass starvation and extreme food insecurity. To combat this challenge, scientists and governments in the region began assessing the value of the Mexican semi-dwarf wheat varieties for their countries. Trials in India and Pakistan were convincing and demonstrated high yields that offered the potential for a dramatic breakthrough in wheat production (CIMMYT 1989).

Borlaug's first visited the region in 1960, when he toured India and Pakistan as part of a team of FAO-Rockefeller Foundation scientists (CIMMYT 1989). Following the visit, Borlaug agreed to provide training for regional wheat scientists and in response Manzoor A. Bajwa became the first Pakistani researcher to arrive in Mexico in 1961. While working alongside Dr. Borlaug and his team in Obregon, M.A. Bajwa identified a medium-to-hard white grain line with a high gluten content that was ideal for making chapatis (flatbread). The new variety also showed promising resistance to rust and powdery mildew. To mark this momentous collaboration, the line was named MexiPak - to indicate that the line selection took place in Mexico by a Pakistani Researcher. In Pakistan, the name MexiPak is synonymous with the successes of the Green Revolution.

Borlaug returned to the region in 1963, at the invitation of a 38-year old Indian wheat cytogeneticist, MS Swaminathan (CIMMYT 1989). Borlaug had sent a few dozen seeds of his high-yielding, disease-resistant semi-dwarf wheat varieties to India to test their resistance to local rust strains. Swaminathan, who like many wheat breeders of the time was interested in testing the semi-dwarf wheat varieties, immediately grasped their potential for Indian agriculture, and wrote Borlaug, inviting him to India. When the unexpected invitation reached him, Borlaug soon boarded a Pan Am Boeing 707 to India. 
To accelerate the potential of Borlaug's wheat, in 1967 Pakistan imported about 42,000 $\mathrm{t}$ of semi-dwarf varieties from Mexico - including 40,000 t of Indus-66, 1,500 $\mathrm{t}$ of MexiPak-65, $200 \mathrm{t}$ of Sonora-64 and $20 \mathrm{t}$ of Inia-66. At the time this was the largest seed purchase in the history of agriculture (CIMMYT 1989).

Wheat yield improvement in both India and Pakistan was unlike anything seen before. In just 4 years between 1963 and 1967, India's wheat harvest doubled to 20 million tons and the nation went from dependence on wheat imports to selfsufficiency. The trend has continued to recent times. In 2012, Indian farmers harvested about 95 million tons of wheat (FAO 2013). A similar effect was experienced in Pakistan. Between 1965 and 1970, wheat production in Pakistan increased from 4.6 million tons to 6.7 million tons (CIMMYT 1989). In 2012, Pakistani farmers harvested over 25 million tons of wheat (FAO 2013).

\section{CIMMYT Today}

In spite of these dramatic impacts the world is still facing enormous challenges in wheat production and we must devise new ways to feed a growing population, with less land, less water and under more difficult circumstances than ever. Production must keep up with increasing demands from population growth and changing diets. Extreme weather events, land scarcity, decreasing groundwater supplies, soil degradation, the impact of diseases, pests and weeds, and a decline in yield improvement are challenges facing global wheat food security.

CIMMYT's Global Wheat Program and the CGIAR Research Program on WHEAT are working to boost farm-level wheat productivity while fortifying wheat's resistance to important diseases and pests and to enhance its adaption to climate change. To meet these challenges CIMMYT is working with national agricultural institutions and the private sector to help develop and apply all appropriate technologies, including molecular breeding, biotechnology, precision agronomy, conservation agriculture and cellphone-based decision support tools.

CIMMYT is leading a global affiliation of top-flight scientists that aims to increase wheat's genetic yield potential by $50 \%$. Approaches being pursued include:

1. Improving photosynthesis to increase total biomass.

2. Improving the partitioning of photosynthates and resistance to lodging, while ensuring that extra biomass is translated to greater grain yield.

3. Stabilizing the physiological and molecular improvements which allow for the expression of agronomic traits responsible for raising wheat yield potential.

CIMMYT's Germplasm Bank constitutes an invaluable resource for wheat improvement. In the Bank, CIMMYT holds in trust one of the largest collections of wheat with 137,692 accessions (CIMMYT 2013). It is a Noah's Ark of genetic 
resources for two of the planet's most important crops (maize and wheat) and CIMMYT seed is made freely available to researchers, private companies and public sector agricultural institutions around the world. The CIMMYT Germplasm Bank is one of only three gene banks globally to achieve ISO certification (and the first outside of Europe) and the only one that has global breeding programs directly attached.

The SeeD project led by CIMMYT is discovering new genes that will help increase yield and prevent crop losses from climate change or disease. Over onethird of the Bank's maize and wheat accessions $(60,000)$ have been tested for heat and drought tolerance and the genome of more than 40,000 have been characterized. In close collaboration with Diversity Arrays Technology (DArT) and Cornell University, the SeeD project has developed a genotyping-by-sequencing (GBS) method for the molecular characterization of wheat varieties. Seed of genotyped plants is then collected and multiplied for subsequent study and use.

\section{Conclusion}

In 1935, when Gonjiro Inazuka selected the semi-dwarf that became Norin 10, little did he imagine that semi-dwarf genes would not only revolutionize the world of wheat but that they would help save more than one billion lives from hunger and starvation. His work has also improved food security for millions of resource-poor farmers in developing countries.

Accepting the Nobel Peace Prize in 1970, Dr. Norman Borlaug said that "man can and must prevent the tragedy of famine in the future instead of merely trying with pious regret to salvage the human wreckage of the famine, as he has so often done in the past."

Today, CIMMYT is building on Dr. Borlaug's vision and carrying forth groundbreaking wheat research. Through state of the art technologies and sound agronomic practices, wheat production can match demand and contribute significantly to global food security and poverty reduction.

For 50 years CIMMYT has been working to eliminate hunger and poverty. Humanity has the creative potential to eliminate hunger and malnutrition in spite of climate change and rising demand, but we need research investment to empower agricultural systems and farmers. The goal is not simply to avoid another food crisis. The goal is to grow enough food sustainably and efficiently to feed the planet.

Open Access This chapter is distributed under the terms of the Creative Commons Attribution Noncommercial License, which permits any noncommercial use, distribution, and reproduction in any medium, provided the original author(s) and source are credited. 


\section{References}

Borlaug N (1981) Breeding methods employed and the contributions of Norin 10 derivatives to the development of the high yielding broadly adapted Mexican wheat varieties. The International Maize and Wheat Improvement Center (CIMMYT) El Batan, Mexico

Borojevic K, Borojevic K (2005) The transfer and history of "reduced height genes" (Rht) in wheat from Japan to Europe. J Hered 96:455-459

Cho CH, Kyu HO, Lee SH (1993) Origin, dissemination and utilization of semi dwarf genes in Korea. In: Miller TE, Koebner RMD (eds) Proceedings of 7th international wheat genetic symposium, Bath Press, Bath, pp 223-231

CIMMYT (1989) Wheat research and development in Pakistan

CIMMYT (2013) Retrieved from CIMMYT Website. HYPERLINK http://www.cimmyt.org/"www. cimmyt.org

FAO (2013) Retrieved from FAO Website. http://faostat.fao.org/

Inazuku G (1971) Norin 10. A Japanese semi-dwarf wheat variety. Wheat Inform Serv 32

Iwanaga M (2009) Norman Ernest Borlaug (1914-2009) Nobel Prize Laureate and Honorary Member of the Japanese Society of Breeding. Breed Sci 59:327-329

Ortiz-Garcia S et al (2006) Transgenic maize in Mexico. Bioscience 56:709

Pinthus MJ, Levy AA (1983) The relationship between the Rht 1 and $R h t 2$ dwarfing genes and grain weight in Triticum aestivum L. spring wheat. Theor Appl Genet 66:153-157

Reitz LP, Salmon SC (1968) Origin, history, and use of Norin 10 wheat. Crop Sci 8:686-689

Reynolds MP, Borlaug NE (2006) Impacts of breeding on international collaborative wheat improvement. J Agric Sci 144:3

Sial MA et al (2002) Genetic impact of dwarfing genes (Rhtl and Rht2) for improving grain yield in wheat. Asian J Plant Sci 1:254-256 